the same direction; these diffuse into the second $n$-type region producing an observable e.m.f. through making collisions with electrons. The second experiment, described by T. P. McLean and E. G. S. Paige (Great Britain), consisted of demonstrating by means of measurements of drift mobility at low temperatures an important drag effect of the majority carriers on the minority carriers. A number of papers dealt with the variation of mobility with temperature and it was clear that in spite of the large amount of work carried out in this field there are still aspects of it which are not properly understood. A considerable number of papers dealt with 'hot' electrons produced by strong electric fields.

Perhaps the outstanding new development reported at the conference was the use of the phenomenon of quantum-mechanical tunnelling, discovered by $\mathrm{L}$. Esaki, as a tool for the study of some of the fundamental properties of semiconductors. By a combination of theory with the study of the voltage-current characteristics of 'tunnel' diodes, it was shown by R. N. Hall (United States) that much valuable information may bo obtained on the phonon energies associated with the band edges of semiconductors such as germanium, and also possibly on polarons in partially polar semiconductors such as the 3-5 compounds. There was, however, some doubt cast, particularly by E. O. Kane (United States), on some aspects of the interpretation of the experimental data.

The optical properties of semiconductors again gave rise to a considerable number of papers (45 if we include photoconductivity), and, as at Rochester, a discussion of excitons played a prominent part. The experiments of S. Nikitine (France) and of E. F. Gross and his colleagues (U.S.S.R.), particularly with cuprous oxide, seem now to be well understood in terme of the theory of R. J. Elliott (Great Britain), an excellent example of international co-operation. The paper by Gross and his colleagues stressed, however, that there is still no convincing direct evidence for exciton transport though its deduction from theory is beyond doubt. They described various optical effects which they have observed in cuprous oxide and which are a consequence of the fact that an exciton is free to move. (The form of the exciton spectra in indirect transitions in germanium and silicon reported at Rochester are also a consequence of the freedom of the exciton to move.) Optical effects in magnetic fields discussed by B. Lax (United States) and others have continued to provide a powerful tool for the investigation of the band structure of semiconductors. Work on the lattice vibrational spectrum of semiconductors is becoming of first importance, and interesting new results were reported by F. A. Johnson (Great Britain). In particular it is of considerable theoretical interest that the T.A. mode in 3-5 compounds such as indium antimonide has a low energy at the zone edge as for silicon and germanium. Surprising new effects in the absorption associated with the reststrahl band in gallium arsenide were also reported by Johnson. Emission of radiation due to inter-band transitions with various phonon combinations reported for silicon by J. R. Haynes, B. Lax and W. F. Flood (United States) and for germanium by Benoit a la Guillaume and $O$. Parodi (France) threw new light on these processes, especially when taking place by means of an impurity centre, and also provided very accurate values for various energies associated with the phonon spectrum. Further information on the band structure of germanium-silicon alloys and of a number of 3-5 compounds was obtained from the accurate measurement by J. Tauc (Czechoslovakia) of optical reflectivity in the visible and near ultra-violet regions of the spectrum. In particular, fine structure was observed which could be interpreted as due to the spin-orbit splitting of the valance band at the zone edge. At the other extreme, photoconductivity was reported in indium antimonide in a magnetic field at $1.7^{\circ} \mathrm{K}$., by R. A. Smith (Great Britain), extending throughout the far infra-red spectrum to wave-lengths beyond $2,000 \mu$.

A considerable number of papers was devoted to the study of ionic crystals and this widened considerably the scope of the conference. In the sessions on new materials, the 3-5 compounds received a good deal of attention, but organic semiconductors wero also discussed by C. G. B. Garrett (United States) and an interesting group of defect compounds such as $\mathrm{In}_{2} \mathrm{Te}_{3}$ by V. P. Zuze and his colleagues (U.S.S.R.).

Perhaps the most mysterious phenomenon discussed without reaching a satisfactory explanation was the occurrence of oscillations in $n$-type germanium and indium antimonide oarrying a current in a longitudinal magnetic field. These appear to be due to plasma effects and were described by P. Aigrain (France) in terms of 'helicons'. Such topics for argument gave spice to what was in any event a very stimulating and thought-provoking conference, which was concluded by an excellent summary of the highlights by $J$. Tauc. This summary was of the greatest help in preparing this report. The conference papers will be published by the Czechoslovak Academy of Sciences in due course.
R. A. SMrTh

\title{
ERGONOMICS IN INDUSTRY
}

\begin{abstract}
A CONFERENCE on ergonomics in industry, organized by the Department of Scientific and Industrial Research, was held in the Connaught Rooms, Great Queen Street, London, during Septembor 27-29. It was attended by more than three hundred representatives of some two hundred industrial firms. The purpose of the conference was to explain the features of ergonomics, to describe some of the ways in which it has already been applied to industry, and to discuss the possible ways in which
\end{abstract}

further use of ergonomic techniques and ideas could be promoted.

Sir Harry Jephcott, chairman of the Council for Scientific and Industrial Research, introducing Lord Hailsham, Minister for Science, who formally opened the conference, said that it was the logical develop. ment of a meeting held in March 1959 in Zurich organized by the European Productivity Agency, and entitled "Fitting the Job to the Worker". At Zurich there were three groups, representing manage - 
ment, trade unions and research workers. In the present conference, he said, industry had provided by far the largest group, although the trade unions were also represented. The research workers were there to present papers and to answer questions, but it was not primarily a scientific congress with discussion between scientists; the scientists' job was to tell their story, and the industrialists on their side were required to comment and to criticize, to try to find out how far the findings and the ideas of the research workers were useful or potentially useful to the industrialists.

In addition to a series of papers, there was a number of exhibits demonstrating application in particular fields provided by the Medical Research Council, General Post Office and several rescarch associations and centres of the Department of Scientific and Industrial Research, notably the British Iron and Steel Research Association, the British Boot, Shoe and Allied Trades Research Association, the Road Research Laboratory, and the Building Research Station. An exhibit on seating had been arranged by the Physiological, Anatomical, British Psychological and the Ergonomics Research Societies, together with the Furniture Development Council.

The papers at the conference were presented under the headings of "What Ergonomics Means", "The Place of Ergonomics in Industry", "Ergonomics and Production", "Ergonomics in the Post Office and in the Steel Industry", "Ergonomies and Products" and the "Future of Ergonomies".

The term 'ergonomics' means the study of the laws of work, and more specifically the study of the relationships between the worker and his cnvironment. Such a study embraces a very wide field, and involves research derived mainly from physiological, psychological and anatomical studies. Up to the present, the Armed Forces have provided the chief field of study, although the term 'personnel research' has boon used to describe the work. Although many of the problems affecting the worker can be described as primarily physiological, such as extremes of heat or cold, or psychological (namely, the presentation of information), or anatornical (namely, the anthropometric data required to design a work space), there are very few eases in which a single-discipline study is adequato. This means that a multi-disciplinary approach is necessary, and the techniques and methods required to develop such an approach are one of the basic problems of ergonomics. However, the problem does not end at this point, since it is clear that engineering aspects are equally important. Without a knowledge of the enginecring problems involved, a solution can be put forward which is either impracticable or exceedingly expensive. At the conference a number of speakers, both in presenting papers and in discussions following papers, emphasized the need to view the problem and its proposed solution in the total setting of industry, that is, to include the worker relationship and trade union views, management and cconomic aspects. It was generally agreed that there is a need to bring biology into industry, but this requires that a proportion of engineers, especially those concerned with the design of equipment, and production engineers, should have somo undergraduate instruction in biology. Equally, biologists require a knowledge and understanding of the complex nature of industrial problems.
Dr. A. Y. Wisner, who is head of the Physiological Section of the Renault Factory in France, illustrated many of these points. He has had to become familiar with the problems of design of motor-cars, with the engineering and production difficulties involved, as well as the economic aspects. He regards himself as an adviser who must not overlook the fact that important and decisive design or economic consideration must have their place in considering requirements for the comfort and safety of the driver. Furthermore, unless the biologist is involved at the beginning of a design study, it is unlikely that he can make a useful contribution, as even apparently small alterations in, for example, the position and angling of pedals can involve expensive re-tooling and extensive re-design.

The importance of engineering was also brought out in a paper by Mr. W. T. Singleton, who was until recently head of the Ergonomics Department of the British Boot, Shoe and Allied Trades Research Association. The sewing machines used in the shoe industry have a simple mochanism for starting and stopping, using a clutch and a continuously rotating fly-wheel. This type has been in use for fifty years or more; but details of the operator's work have changed, becoming in general more complicated. Experiments showed that this form of power transmission is not suitable for producing controlled speeds other than the maximum, and with the more complex tasks the machinists could not always stitch at maximum speed. This apparent paradox was solved by the skill of the machinist in achieving slower than maximum speeds by flicking the clutch on and off at about 3 cycles/sec. The skill required to do this to produce a particular speed was considerable and took time to learn. A variable-speed power transmitter was required, and this needed considerable engineering development before it could be produced in large numbers. A laboratory model was made and a comparison made with the standard machine. The results showed that operators with no machinery experience performed better using the variable-speed control than did skilled machinists using the orthodox control. In the factory there was an improvement in speed of 10-15 per cent. 'This information made it possible to calculate the financial benefit of the now system, an essential factor, as there are about 100,000 machines of this type in Britain. The improvement was clearly worth while, and hence it was considered justifiable to embark on the engineering study needed to produce a now machine.

Three industries in which ergonomics already plays a considerable part are the General l'ost Office, London Transport and the steel industry. Papers were given doscribing the effects of heat in a steel mill, essentially radiant heat which, as Dr. R. F. Hellon said, cannot be eured by ventilation, as one cannot blow away radiation. 'There are three ways in which a severe heat situation can be combated. by reducing the level of work so that heat-loss balances heat-production, or by working at a normal rate and taking frequent rests to cool off, or by reducing heat stress so that normal working is not impeded. The last is clearly the desirable method, but the usual practice in industry is to combine the first and second. Dr. Hellon then outlined possible ways of relieving the heat stress.

Dr. L. G. Norman described the way in which the cab of the now 'Route Master' bus has boon designed by a team which included medical officers, trade 
unionists and engineers. Others joined tho team at different times to advise on seating, ventilation, position of controls and the muscular forces required to operate them. Among the problems was the lack of anthropometric data relating to bus drivers, so calculations had to be based on published measurements of National Service recruits. The need to increase the range of anthropometric data was stressed by other speakers, including Dr. J. S. Weiner, assistant director of the Medical Research Council's Unit on Climate and Working Ffficiency.

The discussion after the papers was in general lively, and there were many useful criticisms. The now familiar problem of communication was frequently mentioned as one of the reasons for the delay in applying biological research to industry. The biologists were advised that industry must not be led to expect that solutions to all its problems are within immediate grasp, and the industrialist was advised that research workers are not good salesmen, but that did not mean they did not have valuable services to offer.

There is, therefore, a strong probability that there will be a considerable demand from industry for biologists and biological advice. The difficulty will be in supply.

O. G. EDholm

\section{ULTRACENTRIFUGATION OF BIOLOGICAL MACROMOLECULES}

$\mathrm{T}$ HERE were about a hundred participants from several countries at the informal meeting on ultracentrifugation organized on behalf of the Faraday Society at Birmingham during September 14-15. Prof. K. O. Pedersen (Uppsala) gave a stimulating historical introduction. Papers by Dr. J. M. Creeth (Lister Institute, London) and Dr. H. G. Elias (Zurich) considered thermodynamical aspects of the sedimentation of multicomponent systems, while Dr. M. Gehatia (Frankfurt am Main) discussed various methods of evaluating $S$ and $D$ constants from the shape of the gradient curve of ultracentrifugation. Dr. G. A. Gilbert (Birmingham) described his theory concerning the analysis of moving boundaries in reversibly aggregating systems; examples of its application being provided in papers by Drs. S. N. Timasheff and R. Townend (Philadelphia) and by Mr. K. A. Cammack (Medical Research Establishment, Porton). A paper by Drs. A. J. Rowe and Dr. P. Johnson (Cambridge) considered the interaction of actin and myosin by ultracentrifugal studies.

Dr. P. A. Charlwood (Medical Research Council, Mill Hill) reviewed trends in the determination of molecular weights of macromolecules from transient state measurements in the ultracentrifuge and Dr. H. G. Elias (Zurich) discussed the various methods of determining the experimental values used in the Archibald expression. Dr. G. Träxler (Munich) con- sidered various ways of using the analytical ultracentrifuge in the measurement of diffusion constants of macromolecules. Papers on the sedimentation of charged macromolecules were presented by Prof. K. O. Pedersen and Dr. R. G. Wallis (Medical Research Establishment, Porton).

A new recording device for the ultra-violet absorption was discussed by Drs. J. B. Th'Aten and A. Schouten (Rijswijk, Netherlands), while Dr. I. Wiedmann (Basle) described a new schlieren optical system. Drs. P. A. Bianchi and K. V. Shooter (Chester Beatty Institute, London) considered the study of the sedimentation characteristics of deoxyribonucleic acid by the ultra-violet system.

Application of zone-centrifugation to the analysis of human serum proteins was described by Dr. D. R. Stanworth, Prof. J. R. Squire and Mr. K. James (Birmingham). Drs. P. Johnson and A. Albert discussed the sedimentation characteristics of human serum macroglobulins.

A suggestion by Prof. K. O. Pedersen that sedimentation coefficients should be referred to $25^{\circ} \mathrm{C}$. rather than $20^{\circ} \mathrm{C}$., as is becoming the practice in the United States, evolked considerable discussion, but no final decision was taken.

Prof. K. O. Pedersen, Dr. A. S. McFarlane (Medica] Research Council, Mill Hill) and Dr. R. A. Kekwick acted as chairmen and Dr. P. Johnson summed-up at the end of the proceedings. D. R. Stanworth

\section{MIGRATION OF MARINE ORGANISMS}

\begin{abstract}
A LATIN American symposium on migration of marine organisms was held at Guayaquil, Ecuador, from June 27 until July 1. It was organized jointly by the Unesco Science Co-operation Office for Latin America and the University of Guayaquil.

It was the fifth of the series of meetings on marine sciences which the Office has held since its foundation in 1949. The previous meetings had, like the Guayaquil one, the double character of symposium and working-party session. They were held at Concepcion, Chile in 1954; São Paulo, Brazil, in 1955; Montemar, Chile, in 1956; and Montevideo in 1957.

Dr. Enrique Rioja (Mexico) was electrid chairman of the symposium and Dr. Hugo Ferrando (Uruguay) acted as secretary. Thirteen marine scientists parti-
\end{abstract}

cipated, from the following countries: Argentina, Brazil, Chile, Cuba, Ecuador, Mexico, Peru, Uruguay. The Unesco Science Co-operation Office for Latin America was represented by Dr. Angel Establier.

The programme of the meeting was as follows: (1) migration of marine organisms, namely (a) fish, (b) invertebrates, $(c)$ cephalopods, $(d)$ birds, (e) other vertebrates; (2) study of environmental factors causing migration, $(a)$ oceanographic factors, $(b)$ biological factors; (3) standardization of methods for studying migratory phenomena, with the view of comparing results; (4) establishment of regional programmes for work on migration of aquatic popula. tions; (5) general discussion of other problems related to migration of marine urganisms. 